\title{
Evaluation of the Antifungal Activity of Aqueous and Alcoholic Extracts of Six Spices
}

\author{
Moses Ikegbunam1, Maduagwu Ukamaka1, Osazuwa Emmanuel2 \\ ${ }^{1}$ Department of Pharmaceutical Microbiology and Biotechnology, Nnamdi Azikiwe University, Awka, Nigeria \\ ${ }^{2}$ Department of Pharmaceutical Microbiology, University of Benin, Benin, Nigeria \\ Email: mn.ikegbunam@unizik.edu.ng
}

Received 11 November 2015; accepted 24 January 2016; published 27 January 2016

Copyright (C) 2016 by authors and Scientific Research Publishing Inc.

This work is licensed under the Creative Commons Attribution International License (CC BY). http://creativecommons.org/licenses/by/4.0/

cC) (i) Open Access

\section{Abstract}

Background: Nigeria is plagued with a variety of socioeconomic problems mainly poverty, poor access to quality healthcare and poor hygienic conditions resulting in the myriad of fungal infections that are frequently encountered in clinical practice. Method: The antifungal activity of aqueous, methanolic, propanolic and benzyl alcohol extracts of Capsicum annuum fruits and seeds, Capsicum chinense fruits and seeds, Aframomum melegueta pods and seeds, Allium sativum bulbs, Allium cepa bulbs and Zingiber officinale rhizomes on Candida albicans (yeast), Aspergillus niger (mould) and Trichophyton rubrum (dermatophyte) were evaluated by the agar well diffusion method. The aqueous and alcoholic filtered plant extracts were obtained by maceration, and also methanolic extracts were also obtained by Soxhlet extraction. The results were obtained by measuring the inhibition zone diameter in millimeters and were presented by subtracting the activity of the control. Results: Aqueous and methanolic extracts of Allium sativum gave the highest inhibition of the growth of Candida albicans $(22 \mathrm{~mm})$, followed closely by its propanolic extract with inhibition zone diameter of $15 \mathrm{~mm}$, and also, propanolic extracts of Aframomum melegueta and $A \mathrm{l}$ lium cepa gave inhibition zone diameters of $12 \mathrm{~mm}$ each. Soxhlet methanolic extract of Allium sativum had the highest inhibition of the growth of Aspergillus niger with an inhibition zone diameter of $25 \mathrm{~mm}$, followed closely by Zingiber officinale Soxhlet methanolic extract with an inhibition zone diameter of $22 \mathrm{~mm}$, also, the propanolic extract of Allium sativum gave an inhibition zone diameter of $21 \mathrm{~mm}$, whereas Soxhlet methanolic extracts of Aframomum melegueta and Allium cepa gave an inhibition zone diameter of $19 \mathrm{~mm}$ each. The highest activity against Trichophyton rubrum was obtained with the Soxhlet methanolic extract of Allium sativum (39 $\mathrm{mm}$ ), followed closely by its propanolic extract with an inhibition zone diameter of $27 \mathrm{~mm}$. An inhibition zone diameter of $22 \mathrm{~mm}$ was recorded with the benzyl alcohol extract of Allium cepa, $22 \mathrm{~mm}$ with the Soxhlet methanolic extract of Aframomum melegueta and $19 \mathrm{~mm}$ with the aqueous extract of Capsicum chinense seeds. Conclusion: The in-vitro inhibitory effects of these spice extracts indicated that the test spices could serve as potential candidates for developing new systemic and topical 
antifungal drugs against the wide range of pathogenic fungal strains, and they could also serve as natural prophylaxis against the fungal infections.

\title{
Keywords
}

\author{
Spices, Antifungal Activity, Agar Well Diffusion
}

\section{Introduction}

People all over the world are still affected by quite a large number of microbial infections with fungi causing a good number of them. It has since been discovered that active medicinal substances are present in plants and this has encouraged the inclusion of herbal remedies in the delivery of health care [1] [2].

Spices are aromatic or pungent plant parts used for enhancing the taste of foods. Although spices are commonly used to improve the taste of foods, they have also been exploited for their medicinal as well as their antimicrobial activities [3] [4].

Capsicum annuum (red pepper) is a fruit spice of the Solanaceae family, rich in proteins, lipids, vitamins, carbohydrates, and health phytochemicals such as carotenoids, flavonoids and capsaicinoids known to prevent diseases such as asthma, coughs, sore throats etc. [5] [6]. Capsicum chinense (Cameroon pepper) is also from the family Solanaceae. It is very popular in the Nigerian market and is used by so many households and individuals.

Aframomum melegueta (Alligator pepper) is from the family Zingiberaceae together with Zingiber officinale (ginger). Alligator pepper seeds have been shown to possess phytoconstituents that have potent antimicrobial effect [7]. Alligator pepper have been found to contain the phytoconstituents; gingerol, methyl-6-gingero, shogaol and paradol that contribute to its antimicrobial properties [8]. Ginger has strong aromatic and medicinal properties [9]. It has been utilized for the treatment of infectious diseases in many countries [10] [11]. The pungent taste of ginger has been attributed to gingerols, shagaols, and zingerone.

Allium cepa (onions) is from the family Amaryllidaceae and contains water, sugar, protein, fat and fibre [12]. Flavonoids and organosulphur compounds are the two major classes of phytochemicals present in onions believed to provide its beneficial health effects [13]. Allium sativum (garlic) also from the Amaryllidaceae family has been used both for its culinary and medicinal purposes [14]. The sulphur containing compounds give them the characteristic flavor and exhibit potent antifungal properties [15] together with the non-sulphur compounds [16]-[18].

Fungal pathogens of humans are grouped as: Yeasts (Candida albicans), Moulds (Aspergillus niger), and Dermatophytes (Trichophyton rubrum). C. albicans is responsible for a wide range of superficial and systemic infections. $75 \%$ of women are affected with genital Candidiasis in their lifetime while in men, alcoholics and diabetics are prone to genital Candidiasis [19] [20]. Aspergillus niger is ubiquitous in nature, exposure is common but disease is rare. Aspergillosis occurs in immunocompromised individuals. A. niger has been implicated in otomycosis in healthy persons. Massive inhalation of A. niger spores can cause allergic reactions such as asthma and pneumonitis. Dermatophytes are fungi that are capable of colonizing the skin, nails, or hair. Trichophyton rubrum is an anthropophilic saprotroph, it colonizes the upper layers of dead skin and it is the most common cause of Tinea pedis, Tinea unguuim, Tinea manuum, Tinea cruris, and Tinea corporis. Infection can be avoided by lifestyle and hygiene modification [19].

The aim of this study is to investigate the inhibitory effects of six commonly used spices on the growth of three pathogenic fungi to determine whether they can serve as natural prophylactics and the possibility of developing systemic and topical antifungal agents with them using the agar well diffusion technique.

\section{Methods}

\subsection{Test Micro-Organisms}

Three microorganisms were tested in this study: Candida albicans, Trichophyton rubrum, Aspergillus niger. They were characterized strains obtained from the Laboratory of Pharmaceutical Microbiology and Biotechnology, Nnamdi Azikiwe University, Awka, Nigeria. 


\subsection{Plant Materials}

In this study, six commonly used spices were selected to analyze their antifungal activity based on previous literature and their popularity in the Nigerian markets. The fresh bulbs of A. cepa and A. sativum, fresh rhizomes of $Z$. officinale, fresh fruits of $C$. annuum, dried fruits of $C$. chinense and pods and seeds of A. melegueta were purchased from Eke Awka and Ose market in Onitsha, Anambra State in the month of April. They were identified and authenticated by Mrs Oduche Anthonia in the Department of Pharmacognosy and Traditional medicine, Faculty of Pharmaceutical Sciences, Nnamdi Azikiwe University Awka.

\subsection{Extraction of Crude Drugs}

The fresh fruits of C. annuum were dried in a hot air oven at $60^{\circ} \mathrm{C}$ for 8 hours. Seeds from some of the dried fruits of C. annuum and C. chinense were separated, along with the seeds of A. melegueta and were powdered separately. The dried materials including the whole fruits of $C$. annuum and $C$. chinense and pods of $A$. melegueta and the separated seeds were reduced to fine powder with a mechanical grinder. The bulbs of A. серa and A. sativum, and the $Z$. officinale rhizome were washed thoroughly using tap water, a clean kitchen knife was used to manually peel the outer coverings, and then the fleshy parts were washed and rinsed with distilled water again. A sterile ceramic mortar and pestle was used to crush the parts into smaller marshy parts. Four solvents were used for the preparation of the extracts namely: cold water, methanol, propanol and benzyl alcohol.

The aqueous extracts were prepared by weighing out $2 \mathrm{~g}$ of the powdered seeds and whole fruits of $C$. annuum, C. chinense and A. melegueta, and $5 \mathrm{~g}$ of the crushed bulbs of $A$. cepa and A. sativum and rhizome of $Z$. officinale, and macerating in $40 \mathrm{ml}$ of cold water in a glass jar. The combination was allowed to stand for 24 hours at room temperature $\left(32^{\circ} \mathrm{C} \pm 2^{\circ} \mathrm{C}\right)$ with occasional agitation. The alcoholic extracts; methanol $99.5 \%$, propanol 99.5\% and benzyl alcohol 99\% were obtained by weighing out same fraction ( $2 \mathrm{~g}$ ) of the powdered whole fruits and separated seeds of $C$. annum, C. chinense and A. melegueta, and $5 \mathrm{~g}$ of the crushed bulbs of $A$. cepa and A. sativum and rhizome of $Z$. officinale and macerating in $40 \mathrm{ml}$ of the $99.5 \%$ methanol, $99.5 \%$ propanol and 99\% benzyl alcohol in a covered glass jar. The combination was allowed to stand for 24 hours with occasional agitation at room temperature $\left(32^{\circ} \mathrm{C} \pm 2^{\circ} \mathrm{C}\right)$. The extracts were then filtered using a Whatman no. 1 filter paper into plastic sample bottles and stored in a refrigerator at $2^{\circ} \mathrm{C}-8^{\circ} \mathrm{C}$. There was altogether nine aqueous extracts, nine methanolic, nine propanolic and nine benzyl alcohol extracts.

The Soxhlet extractor was also used to afford nine different methanolic extracts of the whole fruits and separated seeds of C.annum, A. melegueta and C. chinense, and the bulbs of $A$. cepa and A. sativum and rhizome of $Z$. officinale. The extracts were then stored in a refrigerator at $2^{\circ} \mathrm{C}-8^{\circ} \mathrm{C}$. Altogether, 45 extracts was tested.

\subsection{Identification of Organisms}

Three test tubes of $5 \mathrm{ml}$ sterile Sabouraud dextrose broth was prepared and labeled appropriately and loopfuls of organisms were collected from the stock cultures of C. albicans, A. niger and T. rubrum and placed in the individual test tubes. The organisms were identified using morphological and cultural characteristics.

\subsection{Fungal Identification}

The morphological and cultural characteristics of the fungi isolates were used to identify them. The method that was used is the direct observation of plates. Colony morphology includes the type of pigment (if present), size of colony, texture (opaque, translucent, or transparent), adherence to agar and undulating/round/dentate edge. The plates were observed daily for the rate of growth of each of the isolates. The colour and morphology of the colonies were noted. The base of the plate, odour, were noted.

Standard suspensions containing $10^{5} \mathrm{cfu} / \mathrm{ml}$ of the test organism was made by transferring colonies from the subculture into $5 \mathrm{mls}$ of sterile water and then adjusting and comparing with McFarland's 0.5 standard.

\subsection{Antifungal Activity of the Extracts}

The antifungal activity of these crude extracts was determined against a yeast (C. albicans), mold (A. niger) and dermatophyte (T. rubrum). Agar well diffusion technique was used to determine the antifungal activities of the extracts. $25 \mathrm{mls}$ of molten sterilized Sabouraud's dextrose agar, fortified with $0.05 \mathrm{mg} / \mathrm{ml}$ of chloramphenicol in 
a McCartney bottle was seeded with $0.2 \mathrm{mls}$ of 0.5 McFarland standard suspension of each fungal isolate and poured into appropriately labeled sterile Petri dishes aseptically. The Petri dishes were rotated gently to achieve a uniform distribution of the fungal isolate and was then allowed to set. A standard sterile cork borer of $8 \mathrm{~mm}$ diameter was used to cut uniform wells on the surface of the solidified seeded agar. The wells were then filled with $0.1 \mathrm{ml}$ of each extract with the aid of a sterile syringe and needle. One of the wells in each SDA agar plate was filled with $0.1 \mathrm{mls}$ of sterile water, $99.5 \%$ methanol, $99.5 \%$ propanol or $99 \%$ benzyl alcohol as a control. The plates were then incubated at room temperature $\left(32^{\circ} \mathrm{C} \pm 2^{\circ} \mathrm{C}\right)$ on the laboratory bench for 24 hours $(C$. albicans), 48 hours (A. niger), and 72 hours (T. rubrum) respectively and observed for zones of inhibition. A zone of clearance round each well signifies inhibition and the diameter of the zones were measured in millimeter (mm) and presented by subtracting the activity of the control. This was performed in triplicates for each fungal isolate and extracts and the average of the three readings was taken.

\section{Results and Discussions}

The fungal isolates were identified by their morphological characteristics (Table 1).

The spice extracts differed significantly in their potential to inhibit the growth of C. albicans, A. niger and T. rubrum. Even some of the aqueous extracts had inhibition of the growth of the fungal isolates. The fruits of $C$. annuum and C. chinense had ten (10) seeds each. This seeds were separated, milled and tested alone for their inhibitory effects on the test fungi. The seeds of $A$. melegueta were also purchased from the market, different from the pods, milled, and also tested for antifungal activity.

The highest activity on C. albicans was obtained with the methanolic and propanolic extracts, moderate activity was obtained with the aqueous extracts and the lowest activity was with the benzyl alcohol and Soxhlet methanolic extraction extracts. There was no growth on the C. albicans agar plates filled with the propanol and benzyl alcohol extracts for three and four days respectively. The table below shows the IZD of tested spice extracts on Candida albicans.

Soxhlet methanol extraction gave the best activity on A. niger, propanol gave moderate activity while aqueous and benzyl alcohol extracts gave the lowest activity. There was no growth on the A. niger agar plates filled with the propanol and benzyl alcohol extracts for four days. The table below shows the inhibition zone diameter of the tested spice extracts on Aspergillus niger.

Methanolic extracts gave the highest activity against T. rubrum; aqueous extracts gave intermediate activity, while the lowest activity was obtained with the propanolic extracts. There was no growth on the T. rubrum agar plates filled with the propanol and benzyl alcohol extracts for seven days. The table below shows the inhibition zone diameter of the tested spice extracts against $T$. rubrum.

Significant antifungal activities were evident with extracts of selected spices from members of Solanaceae, Zingiberaceae and Amaryllidaceae families. The result obtained from this study indicated that aqueous or methanolic, propanolic or even benzyl alcohol extracts of dried fruits of $C$. annuum, its seeds, $C$. chinense, its seeds, A. melegueta pods and seeds, A. cepa and A. sativum bulbs and $Z$. officinale rhizomes inhibited the growth of $C$. albicans, A. niger and T. rubrum.

From the Solanaceae family, C. annuum and C. chinense dried fruits and seeds were studied. Only the aqueous extracts of the seeds of $C$. annuum and $C$. chinense inhibited the growth of $C$. albicans. Only the aqueous extract of $C$. annuum seeds inhibited the growth of A. niger whereas the aqueous extract of $C$. annum fruit and $C$. chinense seeds inhibited the growth of $T$. rubrum. This indicates that these peppers have active constituents that inhibit the growth of these fungi. Benzyl alcohol extracts of C. annuum seeds and fruits had no activity on C. albicans indicating that the active constituents might be insoluble in the alcohol. Methanolic and

Table 1. Colony morphology of fungal isolates.

\begin{tabular}{cl} 
Isolate Identification Code & \multicolumn{1}{c}{ Cultural Characteristics } \\
\hline A & $\begin{array}{l}\text { White to cream coloured opaque colonies, with fast rate of growth, } \\
\text { produced in less than } 24 \text { hours. } \\
\text { B }\end{array}$ \\
Fast growing, white, yellow, yellow-brown to black opaque colonies, \\
arranged in whorls. \\
The colonies are opaque, flat to slightly raised, white to cream with \\
a pale brown reverse pigment and a slow rate of growth.
\end{tabular}


benzyl alcohol extracts of $C$. annuum and C. chinense fruits and seeds had no activity on A. niger but the propanol extracts did indicating that their active constituents for antifungal activity are best extracted with propanol. The aqueous and propanol extracts of $C$. annuum seeds had the same inhibition zone diameter $(15 \mathrm{~mm})$ on $A$. niger. The aqueous and methanolic extracts of $C$. chinense seeds inhibited the growth of $T$. rubrum with IZD of $19 \mathrm{~mm}$ and $16 \mathrm{~mm}$ respectively. The aqueous extract had more activity than its methanol and benzyl alcohol extracts on T. rubrum. The propanol extract had no activity.

In the Zingiberaceae family, A. melegueta seeds and pods, and fresh rhizomes of $Z$. officinale was studied. Their aqueous extracts had no activity on C. albicans (Table 2) and A. niger (Table 3) The aqueous extract of $A$. melegueta pods had activity $(18 \mathrm{~mm})$ on $T$. rubrum. The methanolic extract of $A$. melegueta pods and seeds and ginger had activity on A. niger and T. rubrum. A. melegueta had more activity on the three test fungi than $Z$. officinale. In a study conducted by Odetunde et al., 2015, A. melegueta leaves aqueous and methanolic extracts inhibited the growth of $C$. albicans and A. niger with $1 \mathrm{ZD}$ up to $40 \mathrm{~mm}$ in both cases indicating that $A$. melegueta possess phytochemicals with potent antifungal activity [21]. The antifungal activities of A. melegueta have been attributed to phenolic compounds such as gingerol, shagaol, and paradol present in the plant parts [22]. The phytochemical screening of A. melegueta extracts indicated that it contains high doses of tannins, saponins, glycosides and polyphenols than many other weed plants [23].

Only the methanolic extract of ginger had activity on T. rubrum. Also, only the methanolic and benzyl alcohol extract of ginger had activity on A. niger. An inhibition zone diameter of $11 \mathrm{~mm}$ was obtained with ethanolic extracts of ginger against C. albicans in a study conducted by Atai et al., 2009. Similarly, an IZD of $16 \mathrm{~mm}$ was

Table 2. Inhibition zone diameter of tested spice extracts on Candida albicans.

\begin{tabular}{|c|c|c|c|c|c|}
\hline Spices & $\begin{array}{c}\text { Aqueous } \\
\text { Extracts (mm) }\end{array}$ & $\begin{array}{c}\text { Methanolic } \\
\text { Extracts (mm) }\end{array}$ & $\begin{array}{l}\text { Soxhlet Methanolic } \\
\text { Extracts (mm) }\end{array}$ & $\begin{array}{c}\text { Propanol } \\
\text { Extracts }(\mathrm{mm})\end{array}$ & $\begin{array}{c}\text { Benzyl Alcohol } \\
\text { Extracts (mm) }\end{array}$ \\
\hline C. annuum & - & $8 \mathrm{~mm}$ & - & - & - \\
\hline C. annuum seeds & $5 \mathrm{~mm}$ & $5 \mathrm{~mm}$ & - & $3 \mathrm{~mm}$ & \\
\hline C. chinense & - & $8 \mathrm{~mm}$ & - & $3 \mathrm{~mm}$ & $7 \mathrm{~mm}$ \\
\hline C. chinense seeds & $6 \mathrm{~mm}$ & $6 \mathrm{~mm}$ & $7 \mathrm{~mm}$ & $4 \mathrm{~mm}$ & $6 \mathrm{~mm}$ \\
\hline A.melegueta & - & - & $10 \mathrm{~mm}$ & $12 \mathrm{~mm}$ & $1 \mathrm{~mm}$ \\
\hline A.melegueta seeds & - & $8 \mathrm{~mm}$ & & $2 \mathrm{~mm}$ & \\
\hline A.сера & - & $10 \mathrm{~mm}$ & & $12 \mathrm{~mm}$ & \\
\hline Z. officinale & - & $9 \mathrm{~mm}$ & $1 \mathrm{~mm}$ & $5 \mathrm{~mm}$ & \\
\hline A. Sativum & $22 \mathrm{~mm}$ & $22 \mathrm{~mm}$ & $17 \mathrm{~mm}$ & $15 \mathrm{~mm}$ & $4 \mathrm{~mm}$ \\
\hline
\end{tabular}

Table 3. Inhibition zone diameter of tested spice extracts on Aspergillus niger.

\begin{tabular}{|c|c|c|c|c|c|}
\hline Spices & $\begin{array}{c}\text { Aqueous } \\
\text { Extracts }(\mathrm{mm})\end{array}$ & $\begin{array}{c}\text { Methanolic } \\
\text { Extracts (mm) }\end{array}$ & $\begin{array}{l}\text { Soxhlet Methanolic } \\
\text { Extracts (mm) }\end{array}$ & $\begin{array}{c}\text { Propanol } \\
\text { Extracts }(\mathrm{mm})\end{array}$ & $\begin{array}{l}\text { Benzyl Alcohol } \\
\text { Extracts (mm) }\end{array}$ \\
\hline C. annuum & - & - & - & $10 \mathrm{~mm}$ & - \\
\hline C. annuum seeds & $15 \mathrm{~mm}$ & - & - & $15 \mathrm{~mm}$ & - \\
\hline C. chinense & - & - & $14 \mathrm{~mm}$ & $12 \mathrm{~mm}$ & - \\
\hline C. chinense seeds & - & - & $17 \mathrm{~mm}$ & $6 \mathrm{~mm}$ & - \\
\hline A.melegueta & - & $15 \mathrm{~mm}$ & $19 \mathrm{~mm}$ & $13 \mathrm{~mm}$ & - \\
\hline A. melegueta seeds & - & $10 \mathrm{~mm}$ & $12 \mathrm{~mm}$ & $7 \mathrm{~mm}$ & - \\
\hline A. сера & - & $11 \mathrm{~mm}$ & $19 \mathrm{~mm}$ & - & $11 \mathrm{~mm}$ \\
\hline Z. officinale & - & $5 \mathrm{~mm}$ & $22 \mathrm{~mm}$ & - & $7 \mathrm{~mm}$ \\
\hline A. sativum & $20 \mathrm{~mm}$ & $14 \mathrm{~mm}$ & $25 \mathrm{~mm}$ & $21 \mathrm{~mm}$ & $7 \mathrm{~mm}$ \\
\hline
\end{tabular}


obtained with ethanolic extracts of ginger against C. albicans in a study conducted by Supreetha et al., 2011 [24]. This indicates that active constituents responsible for its activity against $C$. albicans are more soluble in ethanol as methanolic extracts used in this study only gave IZD of $9 \mathrm{~mm}$ against $C$.albicans. This study also suggests that the different antifungal agents present in ginger are insoluble in water as none of the aqueous extracts of ginger inhibited the growth of the three test fungi. Gingerols were identified as the major active component in the fresh ginger rhizome [10] indicating that it potential as an antifungal agent. Thus, methanol is a good solvent for obtaining A. melegueta extracts whereas ethanol is better for $Z$. officinale extracts.

A. sativum and A. cepa are members of the Amaryllidaceae family studied. The aqueous and methanolic extracts of garlic had the same activity $(22 \mathrm{~mm})$ on C. albicans. Similarly, in a study conducted by Iwalokun et al., 2004 [17], Suleiman and Abdallah, 2014 [25], an inhibition zone diameter of $27 \mathrm{~mm}$ and $16 \mathrm{~mm}$ respectively were obtained with aqueous extracts of garlic against $C$. albicans. The difference in activity obtained from the aqueous extracts of garlic in the different studies can be attributed to the geographical location, age of plant, time of harvesting, freshness of plant materials, and even the time of harvesting of plant materials. Also, the aqueous extract of garlic had activity on A. niger and T. rubrum. The aqueous extract of onion had activity only against T. rubrum which is in line with the study conducted by Bakht et al., 2013 [26] and Irkin and Korukluoglu, 2007 [27]. Aqueous extract of garlic gave an inhibition zone diameter of $20 \mathrm{~mm}$ against A. niger which is in line with that obtained by Avasthi et al., 2010 [28] (34 mm), Irkin and Korukluoglu, 2007 [25] (16 mm) and Suleiman and Abdallah, 2014 [27] (14 mm). Again, the difference in the inhibition zone diameter can be attributed to the geographical location, age of plant, time of harvesting, freshness of plant materials, physical factors (temperature, light, and water), contamination by field microbes and even the time of harvesting of plant materials. Thus, the aqueous extract of garlic had activity on the three tested fungi. The propanolic extract of onion had more activity on C. albicans than its methanol extract whereas the methanolic extract of garlic had more activity on C. albicans than its propanolic extract as shown in Table 3. This indicates that the active components inhibiting the growth of $C$. albicans are more soluble in propanol (onion) and methanol (garlic) in each case. The propanolic extract of garlic had more activity on A. niger than its benzyl alcohol, methanol and aqueous extract as shown in Table 4. Only the propanolic extract of garlic had activity on T. rubrum, the propanolic extract of the other test spices didn't. The benzyl alcohol extract of onion gave an inhibition zone diameter of $22 \mathrm{~mm}$ against $T$. rubrum which is higher than that obtained with its aqueous and methanolic extracts. A. sativum had more activity than A. cepa. Flavonoids and organosulphur compounds present in onion has been found to be responsible for its antifungal properties [13]. Ajoene present in garlic has been noted to have a potent effect on yeasts, molds and dermato-phytes [16]. Some studies revealed that garlic is as effective as fluconazole at inhibiting C. albicans [17]. When crushed, garlic yields allicin, an antifungal compound and other sulphur containing compounds.

The activity of these spice extracts is comparable to the activity of some synthetic antifungal agents' invitro. In a study conducted by Atai et al., 2009 [29], Nystatin was used as a positive control. Whereas ginger gave an IZD of $11 \mathrm{~mm}$ against $C$. albicans, nystatin produced an IZD of $12 \mathrm{~mm}$. Similarly, fluconazole produced an IZD of

Table 4. Inhibition zone diameter of tested spice extracts on Trichophyton rubrum.

\begin{tabular}{|c|c|c|c|c|c|}
\hline Spices & $\begin{array}{c}\text { Aqueous } \\
\text { Extracts }(\mathrm{mm})\end{array}$ & $\begin{array}{c}\text { Methanolic } \\
\text { Extracts (mm) }\end{array}$ & $\begin{array}{c}\text { Soxhlet Methanolic } \\
\text { Extracts (mm) }\end{array}$ & $\begin{array}{c}\text { Propanol } \\
\text { Extracts }(\mathrm{mm})\end{array}$ & $\begin{array}{c}\text { Benzyl Alcohol } \\
\text { Extracts (mm) }\end{array}$ \\
\hline C. annuum & $10 \mathrm{~mm}$ & $4 \mathrm{~mm}$ & - & - & - \\
\hline C. annuum seeds & - & - & - & - & - \\
\hline C. chinense & $19 \mathrm{~mm}$ & - & - & - & - \\
\hline C. chinense seeds & $18 \mathrm{~mm}$ & $16 \mathrm{~mm}$ & $17 \mathrm{~mm}$ & - & $10 \mathrm{~mm}$ \\
\hline A. melegueta & - & $15 \mathrm{~mm}$ & $22 \mathrm{~mm}$ & - & $12 \mathrm{~mm}$ \\
\hline A. melegueta seeds & & $17 \mathrm{~mm}$ & $18 \mathrm{~mm}$ & - & - \\
\hline A. сера & $12 \mathrm{~mm}$ & $10 \mathrm{~mm}$ & - & - & $22 \mathrm{~mm}$ \\
\hline Z. officinale & - & $9 \mathrm{~mm}$ & $17 \mathrm{~mm}$ & - & - \\
\hline A. sativum & $21 \mathrm{~mm}$ & $19 \mathrm{~mm}$ & $39 \mathrm{~mm}$ & $27 \mathrm{~mm}$ & - \\
\hline
\end{tabular}


$30 \mathrm{~mm}$ when used as positive control whereas aqueous garlic extracts produced an IZD of $27 \mathrm{~mm}$ against C. albicans in a study conducted by Iwalokun et al., 2004 [17].

Soxhlet extraction is a better extraction method than maceration but its high cost could be the reason while it is not usually employed. Macerated methanol extracts of $C$. chinense seeds, A. melegueta pods, its seeds, $Z$. officinale and A. sativum gave inhibition diameters of $16 \mathrm{~mm}, 15 \mathrm{~mm}, 17 \mathrm{~mm}, 9 \mathrm{~mm}$, and $19 \mathrm{~mm}$ respectively against $T$. rubrum whereas their Soxhlet methanol extracts gave IZD of $17 \mathrm{~mm}, 22 \mathrm{~mm}, 18 \mathrm{~mm}, 17 \mathrm{~mm}$, and 39 $\mathrm{mm}$ respectively. Also, macerated methanol extracts of $C$. chinense, its seeds, $A$. melegueta pods and seeds, $A$. cepa, Z. officinale and A. sativum gave inhibition zone diameters of $0 \mathrm{~mm}, 0 \mathrm{~mm}, 15 \mathrm{~mm}, 10 \mathrm{~mm}, 11 \mathrm{~mm}, 5 \mathrm{~mm}$, and $14 \mathrm{~mm}$ respectively against $A$. niger whereas their Soxhlet methanol extracts gave IZD of $14 \mathrm{~mm}, 17 \mathrm{~mm}$, $19 \mathrm{~mm}, 12 \mathrm{~mm}, 19 \mathrm{~mm}, 22 \mathrm{~mm}$, and $25 \mathrm{~mm}$ respectively as shown in Table 4.

The zones of inhibition obtained from extracts of these spices shows that they have great potential as remedies for diseases caused by the test fungi and can even serve as natural prophylactics.

\section{Conclusion}

The study demonstrated that the six spices used had activity on the yeast (Candida albicans), the mould (Aspergillus niger) and the dermatophyte (Trichophyton rubrum). Allium sativum had the greatest activity on all the test organisms signifying that it had greater promise as an antifungal agent. Active constituents with potent activity against tested fungi were also present in the separated seeds of $C$. annuum, C. chinense and A. melegueta. This encouraged the use of these spices for controlling fungal infections and as natural prophylactics. They offered the advantage of being used indefinitely in large amounts.

\section{References}

[1] Tapsell, L.C., Hemphill, I., Cobiac, L, Patch, C.S., Sullivan, D.R., Fenech, M., Roodenrys, S., Keogh, J.B., Clifton, P.M., Williams, P.G., Fazio, V.A. and Inge, K.E. (2006) Health Benefits of Herbs and Spices: The Past, the Present, the Future. Medicinal Journal of Australia, 185, S4-S24.

[2] Tarun, A., Rachana, S., Amar, D.S. and Imran, W. (2012) Antibacterial Activity of Water, Methanol and Ethanol Extracts of Ocimum gratissimum, Vernonia amygdalina, and Aframomum melegueta. Asian Journal of Plant Science and Research, 1, 36-40.

[3] Souza, E.L., Stamford, T.L.M., Lima, E.O., Trajano, V.N. and Filiho, J.B. (2005) Antimicrobial Effectiveness of Spices: An Approach for Use in Food Conservation Systems. Brazilian Archives of Biology and Technology, 48, 92-130. http://dx.doi.org/10.1590/S1516-89132005000500007

[4] Dias, G.B., Gomes, V.M., Moraes, T.M., Zottich, U.P., Rabelo, G.R., Carvalho, A.O., Moulin, M., Gonçalves, L.S., Rodrigues, R. and Da Cunha, M. (2013) Characterization of Capsicum Species Using Anatomical and Molecular Data. Genetics Molecular Research, 12, 6488-6501. http://dx.doi.org/10.4238/2013.February.28.29

[5] Wahyuni, Y., Ballester, A.R., Sudarmonowati, E., Bino, R.J. and Bovy, A.G. (2013) Secondary Metabolites of Capsicum Species and Their Importance in the Human Diet. Journal of Natural Products, 76,783-793. http://dx.doi.org/10.1021/np300898z

[6] Oyagade, J.O., Awotoye, O.O., Adewunmi, J.T. and Thorpe, H.T. (1999) Antimicrobial Activity of Some Nigerian Medicinal Plants, Screening for Antibacterial Activity. Journal of Bioscience research Communication, 11, 193-197.

[7] Galal, A.M. (1996) Antimicrobial Activity of 6-Paradol and Related Compounds. International Journal of Pharmacognosy, 31, 37-43. http://dx.doi.org/10.1076/phbi.34.1.64.13172

[8] Okwu, D.E. (2001) An Improving Nutritive Value of Cassava Tapioca Meal with Local Spices. Journal of Nutraceutical, Functional and Medical Food, 3, 43-51.

[9] Chen, I.N., Chang, C.C., Wang, C.Y., Shyu, T.Y., Ng, C.C. and Chang, T.L. (2008) Antioxidant and Antimicrobial Activity of Zingiberaceous Plants in Taiwan. Plants Foods Hum Nutrition, 63, 15-20. http://dx.doi.org/10.1007/s11130-007-0063-7

[10] Ali, B.H., Blunden, G., Tanira, M.O. and Nemmar, A. (2008) Some Phytochemical, Pharmacological and Toxicological Properties of Ginger (Zingiber officinale Roscoe): A Review of Recent Research. Food Chemistry and Toxicology, 46, 409-420. http://www.ncbi.nlm.nih.gov/pubmed/9927079 http://dx.doi.org/10.1016/j.fct.2007.09.085

[11] Tan, B.K.H. and Vanitha, J. (2004) Immunomodulatory and Antibacterial Effects of Some Traditional Chinese Medicinal Herbs: A Review. Curriculum of Medicinal Chemistry, 11, 1423-1430. http://dx.doi.org/10.2174/0929867043365161 
[12] Sampath Kumar, K.P., Debjit, B., Chiran, J., Biswa, J. and Pankaj, T. (2010) Allium cepa: A Traditional Medicinal Herb and Its Health Benefits. Journal of Chemical and Pharmaceutical Research, 2, 283-291.

[13] Block, E., Gulati, H., Putman, D., Sha, D., You, N. and Zhao, S.-H. (1997) Allium Chemistry: Synthesis of 1-[Alk(en) ylsulfinyl]propyl Alk (en)yl Disulfides (Cepaenes), Antithrombotic Flavorants from Homogenates of Onion (Allium cepa). Journal of Agriculture and Food Chemistry, 45, 4414-4422. http://dx.doi.org/10.1021/jf9705126

[14] Block, E. (2010) Garlic and Other Alliums: The Lore and the Science. Royal Society of Chemistry, Cambridge, 152166.

[15] Reuter, H.D. and Sendl, A. (1994) Allium sativum and Allium ursinum: Chemistry, Pharmacology, and Medicinal Applications. In: Wagner, H. and Farnsworth, N.R., Eds., Economic and Medicinal Plants Research, Academic Press, London, 55-113.

[16] Dikasso, D., Lemma, H., Urga, K., Debella, A., Addis, G., Tadele, A. and Yirsaw, K. (2001) Investigation on the Antifungal Properties of Freshly Pressed Garlic Juice on Major Pathogenic Fungi. Journal of Ethiopian Medical Practitioners, 3, 16-20.

[17] Iwalokun, B.A., Ogunledun, A., Ogbolu, D.O., Bamiro, S.B. and Jimi-Omojola, J. (2004) In Vitro Antimicrobial Properties of Aqueous Garlic Extract against Multidrug-Resistant Bacteria and Candida Species from Nigeria. Journal of Medicinal Food, 7, 327-333. http://dx.doi.org/10.1089/jmf.2004.7.327

[18] Ledezma, E. and Apitz-Castro, R. (2006) Ajoene the Main Active Compound of Garlic (Allium sativum): A New Antifungal Agent. Revista Iberoamericana de Micologia, 23, 75-80. http://dx.doi.org/10.1016/S1130-1406(06)70017-1

[19] Stephen, P.D., Norman, A.H. and Sean, P.G., Eds. (2004) Hugo \& Russell’s Pharmaceutical Microbiology. 7th Edition, Blackwell Science, Hoboken, 44-58.

[20] DeBoer, H.J., Kool, A., Broberg, A., Mziray, W.R., Hedberg, I. and Levenfors, J.J. (2005) Antifungal Activity of Some Herbal Remedies from Tanzania. Journal of Ethnopharmacology, 96, 461-469. http://dx.doi.org/10.1016/j.jep.2004.09.035

[21] Odetunde, S.K., Adekola, I.T., Arungbeto, M.O. and Lawal, A.K. (2015) Antimicrobial Effect and Phytochemical Analysis of Aframomum melegueta on Some Selected Bacteria and Fungi. European Journal of Biotechnology and Bioscience, 3, 15-19.

[22] Okwu, D.E. (2004) Phytochemicals and Vitamin Content of Indigenous Spices of South Eastern Nigeria. Journal of Sustain Agricultural Environment, 6, 30-34.

[23] Odebiyi, O.O. and Sofowora, E.A. (1978) Phytochemical Screening of Nigerian. Medicinal Plants Part II: Iloydia, 41, 1-25.

[24] Supreetha, S., Mannur, S., Simon, S.P., Jain, J., Tikare, S. and Mahuli, A. (2011) Antifungal Activity of Ginger Extract on Candida albicans: An in Vitro Study. Journal of Dental Sciences and Research, 2, 1-5.

[25] Suleiman, A.A., Eltayeb, F.M., Suleiman, S.A. and Osman, N.A. (2015) Antimicrobial Activity of Zingiber officinale (Ginger) Oil against Bacteria Isolated from Children’s Throat. International Journal of Microbiology, 1, 1-6.

[26] Bakht, J., Khan, S. and Shafi, M. (2013) Antimicobial Potentials of Fresh Allium cepa against Gram Positive and Gram Negative Bacteria and Fungi. Pakistan Journal of Botany, 45, 1-6.

[27] Irkin, R. and Korukluoglu, M. (2007) Control of Aspergillus niger with Garlic, Onion and Leek Extracts. African Journal of Biotechnology, 6, 384-387.

[28] Avasthi, S., Gautam, A.K. and Bhadaura, R. (2010) Antifungal Activity of Plant Products against Aspergillus niger: A Potential Application in the Control of a Spoilage Fungus. Biological Forum-An International Journal, 2, 53-55.

[29] Atai, Z., Atapour, M. and Mohseni, M. (2009) Inhibition Effect of Ginger Extract on Candida albicans. American Journal of Applied Sciences, 6, 1067-1069. http://dx.doi.org/10.3844/ajassp.2009.1067.1069 